\title{
Determination of Lead, Arsenic and Chromium Contents in Two Types of Mineral Trioxide Aggregate Using Atomic Absorption Spectrometry
}

\author{
Tabinda Nawaz Khan ${ }^{1}$ \\ BDS, MDS \\ Farhan Raza Khan ${ }^{2}$ \\ BDS, MS, MCPS, FCPS
}

OBJECTIVE: To evaluate the acid-soluble Arsenic, Lead, and Chromium contents in the two varieties of Mineral Trioxide Aggregate (MTA) using Atomic Absorption Spectrophotometry.

METHODOLOGY: Analysis of Arsenic, Lead, and Chromium in the two products of MTS [MProRoot MTA and MTA Angelus] were done using graphite furnace atomic absorption spectrophotometry employing $2.4 \mathrm{~mol} / \mathrm{L}$ of hydrochloric acid for digestion of materials. The test materials were subjected to incubate in water and simulated body fluid (SBF) so that the leach out metal ions from the material can also be quantified. Descriptive statistics reported along with ANOVA for comparison of quantitative analysis of Arsenic, Lead, and Chromium in the extracts of the two MTA products. One way ANOVA was applied to compare the leach out of metals over 15 days. Level of significance was kept at 0.05 .

RESULTS: Both varieties of MTA [ProRoot MTA and MTA Angelus] leached out extracts into water and SBF showing lower values of Arsenic and Lead contents in accordance to the limit set by ISO 9917-1 (2007). However, extracts of both the products had comparatively higher amount of Chromium ions.

CONCLUSIONS: The total amount of Arsenic, Chromium, and Lead released from the two cements were found to be far below than what is considered as clinically harmful.

KEYWORDS: Chromium; Arsenic; Lead, heavy metals; Mineral trioxide aggregate

HOW TO CITE: Khan TN, Khan FR. Determination of lead, arsenic and chromium contents in two types of mineral trioxide aggregate using atomic absorption spectrometry. J Pak Dent Assoc 2020;29(4):223-227.

DOI: https://doi.org/10.25301/JPDA.294.223

Received: 26 August 2020, Accepted: 13 September 2020

$\mathrm{M}$ ineral trioxide aggregate (MTA) has been used as the material of choice for root-end filling material, root furcal perforation repair material and pulp-capping material in the clinical practice. ${ }^{1}$ Despite the favorable characteristics physical properties and biocompatibility of MTA, the cost-effectiveness has been regarded as one of the barriers in its widespread clinical use. $^{2}$ In terms of chemical composition, MTA appears to be similar to the Portland cement. ${ }^{3}$ This cement commonly used in manufacturing of concrete for the building and construction industry. ${ }^{3}$ A number of studies have investigated biocompatibility ${ }^{2}$, physical properties 4 and composition ${ }^{3}$ of Portland cement to explore if it can be used as a viable substitute of MTA. Both products believed to be comparable to each other. ${ }^{2-4}$ The similarity of Portland cement to ProRoot MTA has been documented in a number of studies. ${ }^{1-5}$

1. Assistant Professor, Department of Science of Dental Materials, Dow Dental College, Dow University of Health Sciences.

2. Associate Professor, Operative Dentistry, Dental Section, Department of Surgery, Aga Khan University, Karachi, Pakistan

Corresponding author: "Dr. Tabinda Nawaz Khan”<tabinda.nawaz@duhs.edu.pk>
One of the very important usages of Portland cement is to employ it as a conditioner for industrial waste so that the disposal of sludge produced in the industrial waste containing toxic metals becomes safe. ${ }^{5}$ Portland cement is manufactured in a series of procedures which include mixing of calcareous materials and argillaceous materials and then heating it up in a kiln at $1,450^{\circ} \mathrm{C}$ thereby producing a clinker, which is then grounded with gypsum-forming cement. ${ }^{5}$ The resultant cement may comprise of some toxic metal contamination in the range of 5 to 100 parts per million (ppm). ${ }^{6}$ These toxic metals may include bismuth, Arsenic, Lead, copper, Chromium, iron, zinc, cadmium, nickel, and manganese which are integrated in the cement during its production phases. ${ }^{5}$ As far the toxicity of the Arsenic content in Portland cement is concerned, some previous studies ${ }^{5,6}$ inferred that Portland cement has the potential to be used in lieu of MTA, however it was advised that use of Portland cement should be avoided in clinical practice without verifying the amount of Arsenic in it.

Presence of many transition metals such as Chromium, Lead, Bismuth, Arsenic, Or Mercury are known to cause 
health hazards. ${ }^{7}$ Therefore, due to toxic nature of such elements, it is necessary to analyze their quantities in every day drinking water, food stuff and medicines. ${ }^{7}$ In this respect, a limit is set by ISO for all toxic metals to provide secure boundaries. Whether such elements in the dental restorative materials or cements could leach out and cause harm to the adjacent tissues, has been investigated earlier as well. ${ }^{6}$ To date no standard specifications are documented for Arsenic, Cadmium, Lead, Chromium or other heavy metals are listed in ordinary Portland cements certifications. ${ }^{6}$ For restorative dental materials, ISO 9917-1 (2007) ${ }^{8}$ clearly specifies a maximum limit of $2 \mathrm{mg} / \mathrm{kg}$ and $100 \mathrm{mg} / \mathrm{kg}$ for acid-soluble Arsenic and Lead, respectively. However there is no specification related to even Chromium which is usually present in substantial amount in ordinary Portland cements. ${ }^{5}$

The objective of the present study is to evaluate the concentration of Arsenic, Lead, and Chromium contents in two products of Mineral Trioxide Aggregate (MTA Pro-Root and MTA Angelus) using Atomic Absorption Spectrometry.

\section{METHODOLOGY}

It was a laboratory based investigation employing MTA Pro-Root (Dentsply, Switzerland) and MTA Angelus (Angelus, Brazil) conducted at the Pakistan Council of Scientific and Industrial Research (PCSIR) Karachi, Pakistan. Ethical approval was obtained by IRB (Ref No:-IRB-295/DUHS II). Both MTAs products were mixed according to the manufacturer's instructions, the liquid provided in the ampoule was mixed with the cement content provided in the product sachet.

The mixture was transferred to acid-washed plastic moulds of $20 \mathrm{~mm}$ in diameter and 2-mm deep. The prepared mixtures were then cured at $37^{\circ} \mathrm{C}$ and $100 \%$ humidity for 24 hours. A total of nine discs were made from each product. Six discs were reserved for determining the ion release in solutions while the rest of three discs from each set were selected to determine ion content in the cement materials.

\section{DETERMINATION OF ION CONTENT}

The discs were grounded into fine powder by using agate mortar and pestle. Two grams powdered material was mixed with $50 \mathrm{~mL}$ of $2.4 \mathrm{~mol} / \mathrm{L}$ of hydrochloric acid to produce a slurry paste which was mixed well, and then allowed to settle for 16 hours. The mixture was then centrifuged (Microfuge 16, Beckman Coulter Benchtop centrifuge unit) at the fixed speed of $14800 \mathrm{rpm}$ for 10 minutes. A total of $1,000 \mathrm{mg} / \mathrm{L}$ of stock standard solutions of Arsenic (As), Chromium $(\mathrm{Cr})$ and Lead $(\mathrm{Pb})$ were prepared from their respected salt (Merck, Darmstadt, Germany), in purified water that worked as reagent.

The Arsenic, Lead, and Chromium contents were analyzed using a graphite furnace atomic absorption spectrophotometer (GFAAS; Hitachi Atomic Absorption Spectrophotometer AA-6800; Tokyo, Japan). Measurements were recorded in triplicate and mean values were determined.

\section{DETERMINATION OF ION RELEASE IN SOLUTION}

The rest of reserved set of six cement discs from the two types of MTAs were used to analyze ion released in the simulated body fluid solution (SBF) and water. For that, three discs from each set were placed in water and the other three in the SBF using $25 \mathrm{~mL}$ of fluid. SBF was prepared as suggested by Kokubo and Takadama. ${ }^{9}$ The solutions with discs were incubated at $37^{\circ} \mathrm{C}$ for 2 weeks. The leachate extracts were eventually made up to a standard volume by reagent and were subjected to the measurements for Arsenic, Lead, and Chromium using graphite furnace atomic absorption spectrophotometry.

\section{DATA ANALYSIS}

The data were analyzed using SPSS version 23.0. (IBM, USA) The descriptive statistics were reported as means and SD. Parametric tests were performed as the data were normally distributed. Descriptive statistics computed. ANOVA was applied to compare difference in quantitates of Lead, Chromium, and Arsenic in the extracts. Repeated measure analysis of variance was planned to be applied to compare mean difference over time in leachout of each heavy metal. Level of significance kept at 0.05 .

\section{RESULTS}

The concentration of Arsenic (As), Chromium (Cr) and Lead $(\mathrm{Pb})$ found in the specimens are reported in table 2. Chromium (Cr) had the highest 7.04 \pm 0.06 and $6.07 \pm 0.07$ in the MTA ProRoot and MTA Angelus, respectively. Lead $(\mathrm{Pb})$ had the lowest quantities detected in the two products.

Table 1: MTA products used in the present study

\begin{tabular}{|l|l|l|}
\hline Materials & Description & Manufacturer \\
\hline MTA Pro-Root & White MTA & $\begin{array}{l}\text { Dentsply, Tulsa Dental Products, } \\
\text { USA }\end{array}$ \\
\hline MTA Angelus & Gray MTA & $\begin{array}{l}\text { Angelus Solucoes } \\
\text { Odontologicas, Brazil }\end{array}$ \\
\hline
\end{tabular}

Repeated measure analysis could not be run due to lack of absorbance values detected in water and SBF at 15 days intervals. The mean absorbance values of Chromium $(\mathrm{Cr})$ 
Table 2: Comparison of absorbance values of Arsenic, Lead and Chromium in the leach out extract of two products of MTA

\begin{tabular}{|l|l|l|l|l|l|l|}
\hline \multicolumn{2}{|l|}{$\begin{array}{l}\text { MTA Pro-Root ( } \mathrm{l}=9 \text { ) } \\
\text { Absorbance values (ppm) }\end{array}$} & \multicolumn{3}{l|}{$\begin{array}{l}\text { MTA Angelus ( } \mathrm{n}=9 \text { ) } \\
\text { Absorbance values(ppm) }\end{array}$} \\
\hline Metal & $\begin{array}{l}\text { Baseline } \\
\text { value } \\
\text { (Mean+SD) }\end{array}$ & $\begin{array}{l}\text { 15 days in } \\
\text { water } \\
\text { (Mean) }\end{array}$ & $\begin{array}{l}\text { 15 days in } \\
\text { SBF } \\
\text { (Mean) }\end{array}$ & $\begin{array}{l}\text { Baseline } \\
\text { value } \\
\text { (Mean+SD) }\end{array}$ & $\begin{array}{l}15 \text { days in } \\
\text { water } \\
\text { (Mean) }\end{array}$ & $\begin{array}{l}15 \text { days in } \\
\text { SBF } \\
\text { (Mean) }\end{array}$ \\
\hline $\mathrm{Cr}$ & $7.04 \pm 0.06^{*}$ & 0.00 & 0.01 & $6.07 \pm 0.07^{*}$ & 0.00 & 0.01 \\
\hline As & $1.01 \pm 0.04$ & 0.00 & 0.00 & $0.55 \pm 0.04$ & 0.00 & 0.00 \\
\hline Pb & $0.03 \pm 0.09$ & 0.00 & 0.00 & $0.01 \pm 0.08$ & 0.00 & 0.00 \\
\hline$p$-value & $<0.001$ & NA & NA & $<0.001$ & NA & NA \\
\hline
\end{tabular}

ANOVA was applied at 0.05 level of significance

Tukey's HSD showed that absorbance values of Chromium (Cr) were significantly different in the two products of MTA.

NA: test not applied due to lack of data in the cells.

SBF is simulated body fluid.

were significantly higher compared to Arsenic (Ar) and Lead $(\mathrm{Pb})$ in the two products of MTA. However, the two products were comparable for the quantities of $\mathrm{AR}, \mathrm{PB}$ and $\mathrm{Cr}$ in their leach out extracts.

\section{DISCUSSION}

The present study was aimed to analyze the toxic metals within the MTA material and the quantity that leaches out from material when placed in in water or simulated body fluid.

The detection of metal ions depends on the art of extracting elements from a given solution. ${ }^{10,11,12}$ In this respect Duarte et $\mathrm{al}^{13}$ has suggested using mild acids to extract Arsenic from MTA and Portland cements whereas Karypidou et $\mathrm{al}^{10}$ employed strong acids for dissolution of cements. Some investigators used mixture of two strong acids (like $\mathrm{HCl}$ and $\mathrm{HNO}_{3}$ ) for the same purpose. ${ }^{10}$ The mixture of $\mathrm{HCl}$ and $\mathrm{HNO}_{3}$ in the ratio of 3:1 (aqua regia or King's water) for digestion is the standard method recommended in ISO 11466. ${ }^{12,14}$ Aqua regia method has many benefits including its easier use and being economical. ${ }^{12,14}$ Undoubtedly, this method has turned out to be effective and now widely used for soil related samples. For dental materials, the specified digestion method is documented as standard ISO 9917; the same has been employed in the present study. ${ }^{8}$

A number of studies have evaluated presence of toxic elements in the restorative materials, including MTAs. ${ }^{6,10,15}$ The findings clearly suggest that use of MTA is safe. Arsenic was once considered as the choice of poison for murders. ${ }^{16}$ But in traces, this element is essential for normal body growth and functions. ${ }^{17}$ This study and others ${ }^{10,15}$ demonstrate that Arsenic is present in the MTAs in very little amount and since its quantity is below the threshold specified by ISO, hence the material [MTA] should be considered safe for clinical application.

Similarly, Lead is known to have adverse effects on the neurological system. ${ }^{18}$ Therefore, many studies have been conducted to understand Lead content in the items such as food, snacks and paints etc. and their impact on well-being. ${ }^{18,19}$ In the present study, we infer that quantity of Lead in both MTA Pro-Root and MTA Angelus were far below the toxic threshold and hence safe. This is in agreement with other studies as well. . $^{10,15,20}$

Unfortunately ISO doesn't put any limitation on the Chromium content. The present investigation shows that among all three metals investigated, Chromium was found in the highest quantities. It is potentially alarming situation. Chromium can cause dermatitis, allergic and eczema, mucosal ulcers, perforation of the nasal septum, allergies, asthma, lung cancer, renal pathologies. Once absorbed, it's considered to be retained in the human body and not excreted thus causing permanent damage to the kidneys. ${ }^{21,22}$ To date, the true impact of adverse effect of Chromium on human body is not well understood.

One important aspect of the present study is that it also covered the potential of dissolution and leaching out Arsenic, Lead, and Chromium into water and SBF. Although, the amount were negligible as detected after fifteen days of incubation. However, in another study ${ }^{6}$ considerably more contents were detected. This may be observed due to difference of the experimental methodologies in the two studies.

There are number of techniques used for the analytical detection of metals in a product. The list includes Neutron activation analysis Ion chromatography, atomic absorption spectroscopy, inductively coupled plasma spectrometry, graphite atomic absorption furnace, inductively coupled plasma spectrometry, X-ray fluorescence, Laser induced breakdown spectroscopy and UV-VIS spectrometry etc. ${ }^{11}$ Of all these methods, graphite furnace atomic spectrophotometry is considered as most convenient equipment which can give the most precise results and can detect even the ion content in microns. For the same reason, this instrument was employed in the present study. Other strength of the study is that most investigations have measured the clinical performance and sealing ability ${ }^{23}$ of the MTA ProRoot and MTA Angelus in root defects, but this is the one of the few studies which has investigated the presence of heavy metals in the two types of MTA.

The limitations include in vitro design, lack of thermocycling and not using a Portland cement or any other control. 


\section{CONCLUSIONS}

MTA ProRoot exhibited higher amounts of Arsenic, Chromium and lead compared to MTA Angelus. However, the total amount of these elements in the two products was found to be far below than what is considered as clinically harmful.

\section{AUTHORS' CONTRIBUTION}

TNK carried out the laboratory work and wrote the manuscript. FRK did statistical analysis and critical review. Both authors have contributed substantially and agreed on the final version of the manuscript.

\section{CONFLICTS OF INTEREST}

There are no conflicts of interest regarding this publication.

\section{REFERENCES}

1. Hosoya N, Takigawa T, Horie T, Maeda H ,Yamamoto Y, Momoi $\mathrm{Y}$, et al. A review of the literature on the efficacy of mineral trioxide aggregate in conservative dentistry. Dent Mater J. 2019; 38: 693-700. https://doi.org/10.4012/dmj.2018-193

2. Lenji RK, Nourbakhsh AA, Nourbakhsh N, Nourbakhshc M, Mackenzied K.J.D. .Phase formation, microstructure and setting time of MCM-48 mesoporous silica nanocomposites with hydroxyapatite for dental applications: Effect of the $\mathrm{Ca} / \mathrm{P}$ ratio. Ceramics Int. 2017;43:12857-62.

https://doi.org/10.1016/j.ceramint.2017.06.177

3. Ledesma AF, Santana FHB, Galindo LB, Alatorre JÁA, Ruvalcaba Sil JL. Elemental chemical composition and phase analysis by means of PIXE, DSC, TGA, and DRX of MTA Angelus ${ }^{\circledR}$ and a white Portland cement. Revista Odontológica Mexicana. 2016;20:e182-6. https://doi.org/10.1016/j.rodmex.2016.08.015

4. Borges AH, Guedes OA, VolpatoLER, Filho GS , Borba AM, Zina O, et al. Physicochemical Properties of MTA and Portland Cement after Addition of Aloe Vera. Iran Endod J. 2017;12:312-7.

5. Halim N Ab, Kusin FM, Mohamed KN. Heavy metal exposure from co-processing of hazardous wastes for cement production and associated human risk assessment. Int J Environ Sci Technol. 2018; 15:733-42. https://doi.org/10.1007/s13762-017-1431-y

6. Schembri M, Peplow G, Camilleri J. Analyses of heavy metals in mineral trioxide aggregate and portland cement. J Endod. 2010; 36: 1210-5.

https://doi.org/10.1016/j.joen.2010.02.011

7. Shah MT, Suleman M, Abdul Baqi S, Samiullah1, Sattar A, Khan. Determination of heavy metals in drinking water and their adverse effects on human health. A review.Pure Appl. Biol.2020;9: 96-104. https://doi.org/10.19045/bspab.2020.90012

8. British Standard Institution Dentistry-Water-based cements Part 1: Powder/liquid acid-base cements. ISO EN 9917-1;2007.

9. Myszka B, Schüßler M, Hurle K, Demmert B, Detsch R. Phasespecific bioactivity and altered Ostwald ripening pathways of calcium carbonate polymorphs in simulated body fluid. RSC Adv. 2019; 9: 18232-44.

https://doi.org/10.1039/C9RA01473J

10. Karypidou A, Trikas E, Dimosiar G, Koulaouzidou E, Economides $\mathrm{N}$, Beltes P. Cytotoxicity and metal content of tricalcium silicatebased endodontic cements. Int J Dent Oral Health.2018;4:20-6.

11. Eddaif L, Shaban A, Telegdi J. Sensitive detection of heavy metals ions based on the calixarene derivatives-modified piezoelectric resonators: a review, Int J Envir Anal Chem. 2019; 99:824-53. https://doi.org/10.1080/03067319.2019.1616708

12. Angelopoulou T, Dimitrakos A, Terzopoulou E. et al. Reflectance Spectroscopy (Vis-NIR) for Assessing Soil Heavy Metals Concentrations Determined by two Different Analytical Protocols, Based on ISO 11466 and ISO 14869-1. Water Air Soil Pollut. 2017. Article Number: 436 https://doi.org/10.1007/s11270-017-3609-9

13. Duarte MA, De Oliveira AC, Demarchi, Yamashita JC, Kuga MC, De Campos Fraga S. Arsenic release provided by MTA and Portland cement. Oral Surg Oral Med Oral Pathol Oral Radiol Endod. 2005; 99:648-50

https://doi.org/10.1016/j.tripleo.2004.09.015

14. Shahbazi K, Beheshti M. Comparison of three methods for measuring heavy metals in calcareous soils of Iran. SN Appl Sci. 2019; 1:1541-59.

https://doi.org/10.1007/s42452-019-1578-x

15. Tian J, Zhang Y,Lai Z, Li M , Huang Y, Jiang H et al. Ion Release, Microstructural, and Biological Properties of iRoot BP Plus and ProRoot MTA Exposed to an Acidic Environment. J Endod. 2017;43:163-8

https://doi.org/10.1016/j.joen.2016.10.011

16. Farrell M. Poisons Used in Serial Poisoning. In: Criminology of Serial Poisoners., Cham: Palgrave Macmillan, 2018: 45-68.

https://doi.org/10.1007/978-3-030-01138-3_3

17. Shraim AM. Rice is a potential dietary source of not only Arsenic but also other toxic elements like Lead and Chromium. Arab J Chem. 2017; 10:S3434-43.

https://doi.org/10.1016/j.arabjc.2014.02.004

18. Shvachiy L, Geraldes V, Amaro-Leal Â, Rocha I. Persistent effects on cardiorespiratory and nervous systems induced by long-term Lead exposure: results from a longitudinal study. Neurotox Res. 2020;37:85770.

https://doi.org/10.1007/s12640-020-00162-8

19. Juric AK, Bata Ml, David W, Sharp D, Schwartz H, Ing A.Risk 
assessment of dietary Lead exposure among First Nations people living on-reserve in Ontario, Canada using a total diet study and a probabilistic approach. J Hazard Mater. 2018;344:55-63.

https://doi.org/10.1016/j.jhazmat.2017.09.035

20. Chang SW, Shon WJ, Lee WC, Kum KY. Analysis of heavy metal contents in gray and white MTA and 2 kinds of Portland cement: a preliminary study. Oral Surg Oral Med Oral Pathol Oral Radiol Endod. 2010;109:642-6.

https://doi.org/10.1016/j.tripleo.2009.12.017

21. Barceloux DG. Chromium. J Toxicol Clin Toxicol. 1999;37: 173-94.

https://doi.org/10.1081/CLT-100102418
22. Baruthio F. Toxic effects of Chromium and its compounds. Biol Trace Elem Res. 1992;32:145-53.

https://doi.org/10.1007/BF02784599

23. Hashem AA, Hassanien EE. ProRoot MTA, MTA-Angelus and IRM used to repair large furcation perforations: sealability study. J Endod. 2008;34:59-61.

https://doi.org/10.1016/j.joen.2007.09.007 